\title{
Management of the AIDS Epidemic and Local
}

Global Use of Chinese Medicine

\section{Évelyne Micollier}

\section{(2) OpenEdition}

\section{Journals}

Electronic version

URL: http://journals.openedition.org/chinaperspectives/4776

DOI: 10.4000/chinaperspectives.4776

ISSN: 1996-4617

\section{Publisher}

Centre d'étude français sur la Chine contemporaine

\section{Printed version}

Date of publication: 1 April 2009

Number of pages: $67-78$

ISSN: 2070-3449

\section{Electronic reference}

Évelyne Micollier, « Management of the AIDS Epidemic and Local », China Perspectives [Online], 2009/1 | 2009, Online since 01 April 2011, connection on 28 October 2019. URL : http:// journals.openedition.org/chinaperspectives/4776 ; DOI : 10.4000/chinaperspectives.4776 


\title{
Management of the AIDS
}

\section{Epidemic and Local/Global}

Use of Chinese Medicine ${ }^{(1)}$

\author{
EVELYNE MICOLLIER
}

In the context of a social and medical response to AIDS at a national level recommended by the Chinese authorities, the policy of eventual extension of treatment to all patients reveals "Chinese characteristics" that are akin to international concerns regarding the use of alternative and complementary medicine. One concerns the use of traditional Chinese medicine (TCM), principally in combined treatment (biomedicine with Chinese medicine) in a public health system in which it plays a relatively large part compared to other health systems in the world. This article focuses on the integration of TCM in therapies and research on HIV/AIDS.

$\mathrm{T}$ raditional Chinese medicine (TCM, zhongyi) ${ }^{(2)}$ refers to the Chinese medicine promoted by the Chinese government since the 1950s, and does not include all the remedies referred to as Chinese medicine in the broadest sense. ${ }^{(3)}$ It can be defined as neo-traditional medicine, since elements of biology and modern medicine play a significant part in its dissemination and practice. In the 1990s, the increasing biomedicalisation of "traditional" treatment was driven by two factors, that of the long-term state policy of integrating Chinese and Western medicine and modernising and normalising Chinese medicine, ${ }^{(4)}$ and that of forces arising from cultural and economic globalisation, as manifested in the circulation of scientific as well as traditional ideas and practices around the world and in the economic stakes crystallising around international health in the context of a world market.

In the early twenty-first century, the traditional pharmacopoeia (zhongyao) in its buoyant, state policy-supported form, is tending toward becoming a pharmacotherapy (zhongyiyao), and even a pharmacology of traditional medicine (zhongyiyao xue).

Starting with the recognition that treatment and research in traditional Chinese medicine are an integral part of the public intervention plan for funding the treatment of HIV/AIDS gradually implemented since 2004, I have focused on the modalities of utilisation and integration of this body of knowledge and practice in the management of
AIDS, which I have researched in the context of previous works on therapeutic plurality in China. My article is in two parts, the first of which seeks to contextualise the subject in the framework of the major realignment of health policies in 2004. The second part deals with the integration of TCM in therapies and research on HIV. This process, in its conceptual and operational modes, is concrete evidence of the "biomedicalisation" of TCM that accelerated in the 1990s. In the adaptation of existing and recommended treatments on an international level, combined treatments in biomedicine and TCM are the object of clinical research and practice. In biomedicine it is mainly a question of ARVs (anti-

1. This research was carried in the framework of the IRD-PUMC/CAMS (Beijing Union Medical College/Chinese Academy of Medical Sciences) Project, Social Science Programme, with financial support from the CEFC, Hong Kong. The project was selected in the framework of the call for research projects in 2006.

2. The terms xiyi (literally "Western medicine") and zhongyi (literally Chinese medicine") are used by patients and therapists and in official terminology. I have chosen to use the term TCM (traditional Chinese medicine), which is the official English translation in China of zhongyi, because my approach is from an insider's view (here, official Chinese), which is consistent with an anthropological perspective.

3. For example, local, popular, or family medical treatments (minjian yiliao, difang yiliao/liaofa, etc.), which are not necessarily part of the TCM corpus of practices and treatments.

4. On the initial project of medicine integrated into the construction of a socialist society, see Kim Taylor, Chinese Medicine in Early Communist China, 1945-1963: A Medicine of Revolution, London, Routledge, 2005, 236 pp.; on the modernisation and normalisation of Chinese medicine see Judith Farquhar, Knowing Practice: The Clinical Encounter of Chinese Medicine, Boulder, Westview Press, 1994, 260 pp.; on the construction of one standardised form among others, see Elisabeth Hsu, The Transmission of Chinese Medicine, Cambridge UK, Cambridge University Press, Cambridge Studies in Medical Anthropology, 1999, 296 pp., pp. 88-127. 
retrovirals) applied to AIDS and of other medicines recommended in the treatment of the opportunist illnesses of AIDS, and in TCM it is a matter of treating opportunist illnesses or of developing complementary treatments that might reduce the side effects associated with $\mathrm{ARV}$ s, as well as stimulating the immune system, relieving pain, and working towards increased well-being and a better life for people living with HIV/AIDS (PLWHA). This research aims to adapt existing treatments and develop innovative treatments designed within the protocols as possible substitutes for $A R V$ s. Based on analysis of a number of publications and observations, I will give examples of clinical tests aimed at the scientific certification of AIDS treatments in the wider context of R\&D in TCM.

It should be pointed out that public policy measures taken by China and the long-term political intention to promote traditional medicine come up against the preoccupations of states and civil and economic players on an international level, as well as the WHO's recommendation to integrate traditional medicines in public health systems, promulgated at the International Conference on Primary Health Care in Alma-Ata back in 1978. At that time the Chinese system appeared to be a model to be followed by other states, particularly those with very limited medical resources, in view of the objective of "Health for All in 2000." The Beijing declaration adopted at the end of the WHO First World Conference on Traditional Medicine, held from 7-9 November 2008 in Beijing, ${ }^{(5)}$ is a continuation that calls for wider application of the WHO public policy and strategy guidelines for traditional medicine (2002-2005) initiated in 1978: "Recognizing the progress of many governments to date in integrating traditional medicine into their national health systems, we call on those who have not yet done so to take action." It should be added that the definition of "traditional medicines" is very wide, including a range of therapies, practices, and knowledge that is highly diverse, depending on country and locality, and which can be termed "alternative medicines" or "complementary medicines." (6)

\section{Reformulation of national health policies and integration of TCM}

Beginning in 2004, a new committee at State Council level entrusted with controlling AIDS, aided by more effective monitoring devices, has led to an improved understanding of epidemic dynamics and responses. Knowledge and control of the epidemic have progressed considerably as a re- sult, although many challenges and obstacles remain. Treatment and follow-up of HIV/AIDS is being gradually extended throughout the country, according to the international norms recommended by $\mathrm{WHO}$ for countries with limited resources. For the central government, the challenge today is to implement these new policies in a relatively homogenous fashion at the local level. It would be a mistake, however, to overestimate the responsibility of provincial governments or authorities lower down in the administrative structure, who do not always have the human and financial resources to apply these new measures correctly. ${ }^{(7)}$ Disparities at the regional, administrative, and institutional level, as well as an enduring and widespread stigmatisation of the epidemic and those infected or affected by it, ${ }^{(8)}$ constitute major obstacles to the effective application of new public policies.

It should be mentioned that in December 2003, before the implementation of the national HAART (Highly Active Anti-retroviral Treatment) ${ }^{(9)}$ programme that was in the course of being elaborated, MSF had initiated a programme of confidential treatment and follow-up for patients infected by HIV in Nanning, the capital of Guangxi Province, in collaboration with the provincial CDC (fangyi ju) and the regional Public Health Bureau (weisheng ju). This was a pilot project in China at the time, and was considered a model to be replicated in the official health structures specialising in

5. Available online: http://www.who.int/medicines/areas/traditional/TRM_BeijingDeclarationEN.pdf.

6. The concept of CAM (Complementary and Alternative Medicines) is widely used in medical science, in public health, and in human and social health sciences, including all therapies that do not originate in internationally standardised modern medicine or biomedicine. Such an all-encompassing definition means that it is usually discussed in context in order to be operative rather than being reduced to a theoretical tool.

7. Source: field research carried out by the IRD-PUMC/CAMS research team in sites in the provinces of Hainan and Henan.

8. On firsthand experiences of discrimination against patients with HIV relating to perceptions of AIDS, see Rachel Yunqiu Zhou, "'If you get AIDS... you have to endure it alone': Understanding the social constructions of HIV/AIDS in China," Social Science and Medicine, 2007, vol. 65, pp. 284-295; on discriminatory rumours, perceptions of AIDS and the criminalisation of seropositive people in the media, see Jing Jun, "The Social Origin of AIDS Panic in China," in Joan Kaufman, Arthur Kleinman, Tony Saich (eds), AIDS and Social Policy in China, Cambridge, MA, Harvard University Asia Center, 2006, 267 pp. pp. 152-169; on the phenomenon of stigmatisation at the beginning of the decade, see Evelyne Micollier, "HIV/AIDS-related Stigmatization in Chinese Society: Bridging the Gap between Official Responses and Civil Society," in Alice Desclaux (ed.) HIV/AIDS Stigma and Discrimination: An Anthropological Approach, Paris, UNESCO Publications, Study n 20, pp. 33-46. On perceptions of AIDS in the context of Chinese cultures in 1990s, see Evelyne Micollier "L'Autre: porteur originel et/ou vecteur privilégié du VIH/SIDA (Chine populaire-Taiwan)," in Claude Fay (ed.), "Le sida des autres: constructions locales et internationales de la maladie," Autrepart, 1999, n¹2, pp. 73-86.

9. HAART refers to medicinal regimes combining ARVs to obtain optimal effectiveness; cf DHHS/Henry J.Kaiser Family Foundation Panel on Clinical Practices for the Treatment of HIV infection. Guidelines for the use of antiretroviral agents in HIV-infected adults and adolescents, October 2004 revision, //aidsinfo.nih.gov/guidelines/adult/AA_040705.pdf. 
the treatment and follow-up of AIDS, such as the Number 8 Hospital in Guangzhou. ${ }^{(10)}$

In April 2004, the Ministry of Health, in cooperation with Ministry of Finance and the SATCM (State Administration of TCM, guojia zhongyiyao guanliju), ${ }^{(I)}$ promulgated a series of recommendations aimed at the standardisation of ARV treatments. The set of measures known as "Four Frees and One Care" (simian yiguanhuai) includes free ARVs for all patients resident in rural areas and for patients resident in urban areas who face financial difficulties; free testing and advisory services in high-prevalence areas; free education for children orphaned by AIDS; free testing, advice, and mother-to-child transmission prevention for pregnant women; and financial support for seropositive patients whose financial resources are inadequate. ${ }^{(12)}$

Since the end of 2003, five ARVs (AZT, d4T, ddI, NVP, and IDV $)^{(13)}$ have been produced by pharmaceutical companies based in China, and two others (3TC, EFV) ${ }^{(14)}$ have been imported. These frontline ARV treatments prescribed in China in the framework of the national programme correspond to the norms recommended by the WHO for countries with limited medical resources. A detailed manual has been drawn up to facilitate the implementation of the new policy of treatment and extension of treatment. ${ }^{(15)}$ At the same time, the government has increased investment and development of research into preventive vaccines, $A R V_{s}$, the adapting of $A R V_{s}$ to clinical practice, and TCM products. ${ }^{\left({ }^{(6)}\right)} \mathrm{A}$ large-scale intervention and research programme encourages provinces to test traditional medicine products for the treatment and follow-up of AIDS.

While estimates of the total number of patients benefiting from the HAART treatment in the framework of the national programme vary according to the source and do not always include patients who are following an TCM treatment, UNAIDS and international medical publications indicate that around 20,450 patients received HAART treatment at the end of 2005, 24,400 at the end of 2006, ${ }^{(17)}$ and 32,000 at the end of 2007. ${ }^{(18)}$ At the end of 2006 these included more than 6,000 patients benefiting from a TCM treatment. These data should be viewed with caution, as the figures vary depending on the documents used. While the official rate of the numbers of patients who withdrew from HAART treatment was 8 percent and that of deaths among patients was 10 percent, ${ }^{(19)}$ unofficial sources indicate that the combined rate of withdrawal from treatment and death could reach 50 percent, depending on the locality and the population concerned. On this question, our field data reveal contrasting situations depending on the location and the dominant means of transmission among patients. For example, in Number 8
Hospital in Guangzhou, which specialises in treatment of and research into infectious diseases and includes a treatment department and an AIDS research centre, the combined loss rate among patients on $\mathrm{ARV}$ s, a population with a majority (90 percent) in an advanced symptomatic state ${ }^{(20)}$ and made up of intravenous drug users (70 percent), was around 10 percent in 2007, with a 6 percent death rate and 4 percent rate of withdrawal from treatment. ${ }^{(2)}$ According to our field data, withdrawal behaviour is seen as widespread: some patients readily state that a third or half of patients decide to "withdraw" from the medical treatments prescribed.

Observance and adherence to ARV treatment are crucial both for effectiveness and in reducing resistance. ${ }^{(22)}$ The

10. Source: research carried out among the nursing team, clinicians, and researchers in January 2008, and among members of local NGOs in January 2005, including AIDS Care based in Guangzhou, which was recognised for its exemplary action in the 2000s. This organisation was founded in 2002 by Thomas Cai, an activist who had the courage to make public his HIV-positive status, and built a very good reputation among various local national and international actors engaged in AIDS intervention in China. Thomas Cai contributed to the reference work published in 2006 on AIDS and social policy in China, edited by Joan Kaufman et al, op. cit., chap. 8, pp. 170-174.

11. The SATCM is an organisation that is part of the Ministry of Health (Weisheng bu). Its director general, Wang Guoqiang, is also Deputy Minister of Health.

12. Jennifer Pan, China National Free Antiretroviral Therapy Program, Beijing, Chinese Center for Disease Control and Prevention, National Center for AIDS/STD Prevention and Control, June 2005.

13. Respectively Zidovudine, Stavudine, Didonosine, Nevirapine, Indinavir.

14. Respectivement Lamivudine, Efavirenz.

15. China Free ART Manual, Chinese Center for Disease Control and Prevention (CDC), January 2005, $68 \mathrm{pp}$. We should note that a much more precise and complete revised edition, based on updated data, appeared in 2008, $212 \mathrm{pp}$.

16. On research and management of AIDS based on the adaptation of the biomedical model rather than the traditional model, cf. Evelyne Micollier, "Facettes de la recherche médicale et de la gestion du VIH-sida dans le système de santé chinois: un autre exemple d'adaptation locale de la biomédecine," Sciences Sociales et Santé, 2007, vol. 25, n³, pp. 31-39.

17. Bates Gill, Susan Okie, "China and HIV—A Window of Opportunity," New England Journal of Medicine, 2007, vol. 356, n¹8, pp. 1801-1805.

18. Updated data from the 2007 report, Key Data UNAIDS, http://www.unaids org.cn/en/index/ page.asp?classname=Key+Data\&id=178\&class=2, consulted on 15 January 2009; including 6,000 in Yunnan, one of the regions most affected by the epidemic since its emergence, cf. Wang Jiang, Wang Yan, "6,000 AIDS patients in Yunnan receive free treatment," Xinhua, 30 November 2007.

19. National Center for STD/AIDS Prevention and Control, unpublished report on ARV Treatment Situation, June 2005.

20. Most of the patients received prior treatment for opportunist infections such as tuberculosis

21. Field research carried out in January 2008 on the hospital site among the medical team context of data collection: working meetings where clinical practice, treatment, and followup problems were discussed. Also taking part were members of the hospital management and of the local nursing and research team, students in specialised medical training, and two experts/researchers in HIV/AIDS, one an epidemiologist and the other an immunovirologist on a mission from my laboratory IRD, UMR 145 "VIH et maladies associées."

22. Observance refers to the following of treatment in reality, in an objective manner; adherence refers more to the perceptions and representations of the patient concerning his treatment and its effectiveness in their common meaning diverge from or converge with medical or biological meaning. We should also point out that since 2006, a monitoring and control system has been established, cf. UNAIDS, A Joint Assessment of HIV/AIDS Prevention, Treatment and Care in China (2007), State Council AIDS Working Committee Office, UN Theme Group on AIDS in China, 1 December 2007, 38 pp., p. ii. 
problem of observance is emphasised by epidemiologists and public health specialists, ${ }^{(23)}$ who say that patients need to be better informed and specific strategies should be developed for those with a very low level of education. The administration or use of traditional medicines to treat HIV or AIDS has not posed any significant problem, ${ }^{(24)}$ these treatments being generally better accepted by patients.

Lastly, in the framework of the new policies, new institutional models piloted and supported by the SATCM are being set up, bringing together research structures, hospitals, and university training institutes. These include the AIDS research section of the National Association of TCM in Zhengzhou, and the AIDS research institute at the TCM University of Henan. In Beijing, the organisational structure had been redesigned previously: the traditional medicine organisations specialising in the treatment and follow-up of AIDS include AIDS treatment centres (aizibing liaofa zhongxin) such as that at the Guang'anmen Hospital (GAMH AIDS Clinical Centre), one of the hospitals of the National Academy of Chinese Medical Sciences that works in collaboration with research structures such as the AIDS department of the same University. In 2000, a clinical research department, an AIDS treatment centre, and laboratories for testing, diagnosis, and analysis of viral load, were set up within Guang'anmen Hospital.

\section{Extension of treatment and integration of TCM in the national plan: A diachronic perspective and the present situation}

Since the 1980s, the Chinese government has shown political determination to enhance the value and explore the potential contribution of TCM to the prevention, treatment, and follow-up of AIDS. This determination has been further reinforced since the realignment of public policy in 2004: according to Wen Jiabao, ${ }^{(25)}$ "the objective is to develop integrative methods of Chinese and Western medicine aimed at treating AIDS, and to this end, the resources of TCM must be completely exploited." Deputy Prime Minister Wu Yi also emphasised the importance of TCM during the National Working Meeting of Prevention and Treatment of AIDS that was held in the same year. We should note that the necessity of developing integrated treatment through the contribution of TCM was already indicated in official documents dealing with controlling the AIDS epidemic at the end of the 1990s and the beginning of the 2000s. ${ }^{(26)}$ In real terms, the organising and coordinating group on the prevention and treatment of AIDS was formed later in 2004 by the SATCM, drawing up the first project for the development of TCM for the treat- ment of AIDS (Project of AIDS Prevention and Treatment with TCM of SATCM, 2004-2005). A series of public policy measures and regulations promulgated by the SATCM and the Ministry of Health followed. ${ }^{(27)}$

In terms of research, before the discovery and marketing of ARVs began in 1998, the Ministry of Science and Technology (Keji bu) had in the 1980s identified the development of TCM for the treatment of AIDS as a major project of public research in biological and medical science. In fact, clinical trials of treatment of AIDS with TCM were carried out in Tanzania in 1987: a group of researchers from the $\mathrm{Na}-$ tional TCM Research Institute, an academic institution that has since been raised to the status of an academy and renamed National TCM Academy in Beijing, then headed by Lu Weibo, director of the institute's AIDS department, was sent to Tanzania, where Chinese medicine was already widespread and appreciated, ${ }^{(28)}$ to conduct exploratory research. The official explanation for the delocalisation of this research cited the fact that the pool of patients identified in China was too small to satisfy the criteria for inclusion in a test. These studies were carried out until 1995, with the results reported in a number of publications. ${ }^{(29)}$ The consensus

23. See Zhang Konglai, Roger Detels, Liao Susu, Myron Cohen, Yu Dongbao, "China HIV/AIDS epidemic: Continuing challenges," The Lancet, 20 October 2008, p. 2, published online at www.thelancet.com; Wang Xiaoqi, Wu Zunyou, "Factors associated with adherence to antiretroviral therapy among HIV/AIDS patients in rural China," AIDS, $2007 \mathrm{n}^{\circ} 21$, Suppl. 8, pp. S149-156.

24. Zhang Konglai et al., op. cit.

25. Speech on 9 July 2004 entitled "All of society must mobilise to prevent and control AIDS effectively."

26. "Program on Middle and Long Term Prevention and Controlling of AIDS in China (19982010)" and "Action Program on Prevention and Treatment of AIDS in China (20012005)." We should recall that this was also the period when ARV treatments were introduced and became widespread in clinical practice at a global level.

27. "Clinical Technical Project of AIDS Treatment with TCM"; "Management Project of Tria Items in AIDS Treatment by TCM"; "Details of Clinical Technical Project on AIDS Treatment by TCM in Five Provinces (Henan, Hebei, Anhui, Hubei, Guangdong)"; "Recommendation on Guidelines of Diagnosis and Treatment of AIDS"; "Clinical Technical Project on AIDS Treatment with TCM"; cf. Wu Gang, "Status and Prospect in Preventing and Treating HIV/AIDS with Traditional Chinese Medicine," Chinese Journal of Integrative Medicine (Zhongguo jiehe yixue zazhi), 2006, vol. 12, n², pp. 81-84, English language edition.

28. We should recall that Chinese medicine was introduced into Tanzania in the 1970s thanks to the close links established between the Chinese and Tanzanian governments. Chinese medical teams were sent by the central and provincial governments to work in the country's district hospitals. Cf. Elisabeth Hsu, 2002, "'The medicine from China has rapid effects": Chinese medicine patients in Tanzania," Anthropology\&Medicine, vol. 9, n³, pp. 291-313.

29. A (non-exhaustive) summary of the protocols, hypotheses, and results of research carried out in the 1990s is provided in Lu Weibo, Traitement du sida par la médecine et la pharmacopée traditionnelles chinoises: Huit cas de conversion séronégative, translated from the Chinese by Mo Xuqiang, Paris, Quimétao, 1998, 127 pp. Lu also refers to research carried out in China and its results published in Chinese journals such as zhongyi zazhi (TCM Journal), Zhongyi xueyuan xuebao (TCM Institute review), Zhongyiyao xuebao (TCM pharmacopeia review), Zhongguo zhongxiyi jiehe zazhi (Chinese journal of integrated traditional and Western medicine); further information and clinical tests are reported in Zhong Dajin, Wang Xuao, Zhao Shuzhen, Fu Lining (compilers), Aizibing de zhongyi zhiliao (Treatment of AIDS with TCM), Beijing, Zhongguo Shandong kexue jishu chubanshe (Shandong Science and Technology Press), 1992, 127 pp. 
among researchers today is that methodological shortcomings produced biases and led to highly questionable results such as cases of "negative seroconversion." (30)

Official discourse on the subject highlights three stages in the research in progress over the past 20 years and its clinical application to HIV treatment: the exploratory stage in Tanzania (1987-1995) consisted of acquiring general knowledge and building up clinical tests; the stage of preliminary research (1995-2003) was characterised by observations made possible by the TCM treatment of patients in areas where the epidemic had developed in China; simultaneously, medicinal plants were tested in laboratories and selected for their anti-HIV effects. Lastly, since 2003, the third stage has centred around the standardisation of the products identified and their development for possible marketing. ${ }^{(31)}$

We should note, however, that the ethical problems raised by this research have rarely if ever been mentioned up to now. This situation is worrying, as the first two stages, one delocalised to Africa and the other relocalised to China, apparently prolonged while waiting for the introduction of a national programme in certain regions and localities, imply the treatment of under-informed patients, first by monotherapy with AZT for the treatment of HIV after 1994, and then by multitherapies introduced in 1996. In fact, access to ARVs was limited to patients who could afford them, because there was no reimbursement before the launch of the national programme in the context of the public health system.

\section{Combined/complementary treatment: some fragmentary but meaningful data}

We note a time lag between the political determination stated for two decades and the progress of research toward widespread application of a product in everyday clinical practice. This situation has not yet come about in reality, but is in pilot clinical or everyday practice, depending on the locality, with the introduction of the Tang herbal tablet, which was finally approved for the treatment of HIV infection in 2006 by the SFDA $^{(32)}$ and is today recommended at the national level as a complementary treatment with HAART. This recommendation is not unanimously approved among healthcare workers and administrative cadres in the health system, however. For example, in Number 4 Hospital in Nanning, where the Tang tablet is prescribed in accordance with the recommendation, some members of the AIDS, Infectious Disease and Hepatitis Department, and some hospital cadres, say it will take some time to confirm the effec- tiveness of the herbal tablet. To them and to other members of the medical staff, TCM products cannot be validated by clinical trials as in biomedicine, but only by "old-fashioned" clinical experience, according to which effectiveness can only be confirmed over a long period of time, stretching over generations. At the MSF clinic in Nanning, which cooperates with this hospital, members of the medical staff believe that the product can't do any harm, but its use was not promoted because TCM products have a certain cost, and the association could not pay for medicine that is not certified at an international level. ${ }^{(33)}$ In Guangzhou, at the Number 8 Hospital that has an AIDS department, collaboration is closer between the medical, TCM research, and biomedicine staff because a TCM dispensary operates within the department, combining everyday clinical practice with research carried out with the traditional medical University. Around ten beds are reserved for patients volunteering for joint treatment, and patients being treated at Number 8 Hospital were recruited for a test being carried out at the traditional medicine university. An interesting but very worrying aspect of the test underway is the number of dropouts, ${ }^{(34)}$ which repeatedly reached 30 percent, since the number of other patients newly included equalled that of those who "left" the research protocol. ${ }^{(35)}$

Lastly, returning to a macrosocial rather than a microsocial analytical perspective, we should note that beyond the politically correct discourse heard in certain meetings, the share represented by TCM in China CIPRA (China Comprehensive Integrated Programs for Research on AIDS) projects and their publications is limited. ${ }^{(36)}$ Moreover, TCM was referred to in a UNAIDS report for the first time in 2007, in a section dealing with the treatment of opportunist

30. Title of Lu Weibo's book, op. cit.

31. Wu Gang, art.cit., p.83.

32. We should nevertheless mention that in 2006 this national organisation was implicated in a series of serious scandals concerning the health safety of food and medicinal products, events widely reported in the official Chinese press by Xinhua, China Daily, etc., and internationally by Reuters, among others. These scandals undermined its authority and led to severe penal sanctions, including the execution of the organisation's former head in July 2007.

33. Interviews and observation carried out during field research in January 2008: visits to Number 4 Hospital and to the MSF clinic in Nanning.

34. In the framework of the HAART-TCM programme: some patients rejoined the non-combined HAART programme.

35. Id.: visits to the departments and research laboratories in Number 8 Hospital and to the traditional medicine university.

36. See China CIPRA Reference book, China CIPRA Overview, 2007, 253 pp., and China CIPRA's Publications Book, 2007, 340 pp., published by China CIPRA, www.ciprancaids.org.cn. The CIPRA programmes implemented at a global level, an initiative supported by the US NIH (National Institutes of Health), are part of the world research agenda of NIAID (National Institute of Allergy and Infectious Diseases) established in response to the global HIV/AIDS epidemic. 
illnesses: "The treatment project has been extended to fifteen provinces where over 6,000 patients receive it. Under treatment, the condition of patients has improved and some have been able to resume their professional activity. ${ }^{(37)}$ The national pilot project on the use of TCM for the treatment of HIV/AIDS implemented in Guangxi and Yunnan beginning in 2005 shows encouraging results, with a reduction in clinical symptoms, a better quality of life, and no side effects or unfavourable reaction reported in the local press. ${ }^{(38)}$ Moreover, an example of the use of the pharmacopoeia aimed at preventing the transmission of HIV through the sharing of contaminated needles by intravenous drug users, which remains a common means of transmission (after being the dominant means of transmission until 2005), was reported in 2008. The formula being tested can help end drug use: "It has particular properties which fight psychological addiction and anxiety, and prevent relapse." ${ }^{(39)}$

\section{Research in traditional medicine and treatments for HIV/AIDS}

In the first part of this section, I will deal with social and economic usages, including aspects of economics and the philosophy of knowledge. The second deals more specifically with the methodology of clinical testing as well as with treatments and research into AIDS. The last part, which refocuses on the Chinese world after a look at international research, seeks to provide information on tests of treatment for AIDS in China.

\section{The social, economic and scientific usages of TCM in China}

I will briefly summarise the socio-cultural and economic context of the use of TCM in China today. Chinese medicine is one of the icons of Chinese identity. For some time, it has been widely used by the authorities in the context of a more widespread revitalisation of certain aspects of Chinese culture, such as the reassertion of the value of the architectural and artistic heritage, and of an education based on "Confucian" values dispensed by the Confucius Institutes. ${ }^{(4))}$ These phenomena of "heritage-isation" and revitalisation of elements in the cultural repertoire have been identified in many societies, and are always associated with social change. In this context one can speak of a tendency to heritage-ise medical knowledge - the problem is determining which knowledge - that is expressed in a diffuse or affirmed manner in
Chinese society today. Concern for the "medical tradition" has manifested itself in the desire of some categories of the population, who are witnessing this trend towards the "biomedicalisation" of Chinese medicine particularly in research methods, to remove TCM from the Chinese public health system and to question the idea of integration (jiehe yixue, yiliao) and synthesis (zonghe yixue, yiliao) of medicines. However, we should recall that "integrative" or "hybrid" practices and knowledge have developed since the 1950s, particularly during the time of the Cultural Revolution (1966-1976) in China, supported by a strong political determination that shaped a consciously formulated hybridisation and a "top down" syncretism. ${ }^{(4)}$ In an accepted sense that has been widened to include other socio-cultural contexts and other forms of medical knowledge, they are also developing rapidly, and have been validated at an international level with recommendations and declarations of the WHO favouring the insertion of TCM in national health systems since 1980.

To return to the concern for Chinese medicine reflected in popular rather than official discourse, it is worth noting a debate that reached an unexpected scale at the end of 2006 following the online publication of an article by Professor Zhang Kongyao, a science philosopher at Hunan's University of Changsha, which he posted on his blog, and in which he questioned the insertion of Chinese medicine into the public health system. The question at the heart of the debate turns out to be much more subtle than the a priori Manichean one of "for or against" TCM in public medicine or in general that resulted from distortion of the issue through media dissemination. Zhang did not radically oppose zhongyi, but called into question the process of institutionalisation of this medicine in the framework of schools, institutes, and universities that teach Chinese medicine

37. A Joint Assessment of HIV/AIDS Prevention, Treatment and Care in China (2007), State Council AIDS Working Committee Office, UN Theme Group on AIDS in China, 1 December 2007, 38 pp., p. 25

38. Chen Yihua, Wei Yishan, Jiang Xian, "Many benefits to treating HIV/AIDS with Traditiona Chinese Medicine," Nanning Evening News, 18 December 2007; Cai Xiangrong, "1,658 AIDS patients in Yunnan receive free treatment with Chinese Medicine," Xinhua, 28 September 2007.

39. "Specialized Chinese medicine shows quick results for quitting drugs," 2 January 2008 http://nb.qianlong/htlm/news/20081/73379.htm, posted on the site of the NGO www.china-aids.org, visited on 15 January 2009.

40. For an analysis of references to Confucianism and to "cultural tradition" in official discourse in the 2000s, see Sébastien Billioud, "Confucianism, 'Cultural Tradition,' and Official Discourse in China at the Start of the New Century," China Perspectives, 2007, n³, pp. 50-65.

41. Cf. Sydney D. Whyte, "Deciphering 'integrated Chinese and Western Medicine' in the rural Lijiang basin: State policy and local practice(s) in socialist China," Social Sciences and Medicine, $1999, n^{\circ} 49$, pp. $1333-1347$. 
(zhongyi xuexiao, xueyuan, daxue). ${ }^{(42)}$ In his view, zhongyi cannot become a discipline in the academic system because traditional medicine is characterised by its holistic dimension and its historic, philosophical, and philological links with literature, poetry, and painting: for example, some prescriptions were calligraphed poems. ${ }^{(43)}$ Zhang suggested returning TCM to the domain of "popular remedies" (minjian yiliao) and reasserting its value through hereditary family or spiritual ${ }^{(44)}$ transmission and practice exercised in the framework of "popular" social organisations (minjian hui/pai), a means of shedding light on the futility of questions about modernisation and the construction of the evidence according to the norms of the biomedical sciences. ${ }^{(45)}$

Moreover, in these times of economic and cultural globalisation, Chinese remedies appeal to the new middle class in China and already make up an important part of the global market for complementary and alternative medicines, and are thus potentially lucrative. ${ }^{(4)}$ We can therefore hypothesise that traditional medicine in its widest sense is, at the international level, the most commonly used repertoire of therapies among non-biomedical medicines.

In the economic sphere, TCM research and development lies within the framework of the world health market because of the potential marketing of pharmacotherapy (zhongyiyao) and traditional pharmacology (zhongyiyao xue) products. These products could become a welcome niche market for the Chinese pharmaceutical industry ${ }^{(47)}$ in the wake of constraints linked to China's access to the WTO, ${ }^{(48)}$ when these companies can no longer systematically manufacture the generic versions of biomedical products patented in the developed countries that previously made up 97 percent of their production. The development of TCM pharmacology shows an orientation towards the merchandising underway in consumer societies by participating in globalised methods of promoting traditional medicines: the marketing methods and packaging of TCM products are becoming increasingly similar to those originally used in the United States for dietary supplements (vitamins, anti-oxidants, etc.) and which subsequently spread worldwide, including a number of products and preparations that are available without a prescription (over the counter, or OTC). ${ }^{(49)}$ In her research into the factors that led African peoples and governments to adopt Chinese medicine in the 1990s, Elisabeth Sue has emphasised that economic factors could not be underestimated, even though other factors such as the socialist orientation of political ideology, the upward social mobility of patients, and the treatment strategies of actors attracted to this medicine out of curiosity or as a last resort, also play a part in the spread of TCM. ${ }^{(50)}$

We have noted that while present at negotiations on the development of international research in Chinese medicine, the strategy of China's industry and the authorities - the industry being mainly controlled by the State - was to obtain a licence to sell in developed countries by registering the compositions of the pharmacopoeia in the medical rather than dietary supplements category. The legal scientific validation framework is much more constraining, implying a resort to the $\mathrm{EBM}^{(51)}$ model and the carrying out of conclusive $^{(52)}$ (which is not to say successful) clinical tests. Besides the objective of validation and recognition of a "medical tradition" by the process of "scientific" legitimisation of Chinese medicine, there seems to be a primarily profit-seeking aim.

42. On schools, university TCM curricula, the administrative organisation of studies, and the content of teaching, see Elisabeth Hsu, op. cit., 1999; Eric Marié, "Mutations et enjeux d'un système médical traditionnel confronté à la modernité," Monde chinois, 2005 $\mathrm{n}^{\circ} 5$, pp. 101-124.

43. Joseph S. Wu, "Understanding Chinese Medicine: A Philosophical and Cultural Approach," Asian Thought and Society, 1998, vol. 23, n68, pp. 123-129, p. 125.

44. From master to disciple, training by a lao zhongyishi, a traditional doctor respected because he is recognised as competent.

45. Cf. Evelyne Micollier, "Transformations de la médecine chinoise en Chine: recherche et développement, circulation des savoirs et des pratiques," session "Les médecines d'Asie aujourd'hui. Trans-nationalisation des pratiques et relocalisation des savoirs," Conference of the Asia Network (Rasiem), conference paper, 26-28 September 2007 Paris, 10 pp., accessible online at www.reseau-asie.com.

46. Elisabeth Hsu, "La médecine chinoise traditionnelle en République populaire de Chine," with Anne Cheng, La pensée en Chine aujourd'hui, Paris, Gallimard, 2007, 478 pp., pp. 214-238, pp. 237-238.

47. This is still largely in the public sector, although it is undergoing gradual privatisation.

48. December 2001.

49. For examples of alternative treatments for AIDS in Asia and Africa, see Anita Hardon, Alice Desclaux, Marc Egrot, Emmanuelle Simon, Evelyne Micollier, Margaret Kyakula, "Alternative medicines for AIDS in resource-poor settings: Insights from exploratory anthropological studies in Asia and Africa," Journal of Ethnobiology and Ethnomedicine, 2008, n4 16 pp.; Elisabeth Hsu, "Medicine as Business: Chinese Medicine in Tanzania," in Chris Alden, Daniel Large, and Ricardo Soares de Oliveira (eds), China returns to Africa: A Rising Power and a Continent Embrace, London, Hurst, 2008, 400 pp., pp. 221-235.

50. Elisabeth Hsu, op. cit., 2002, p. 310; for insight into the point of view of international relations on South-South globalisation of Chinese medicine, with the case study of Tanzania, see Michael Jennings, "Chinese Medicine and Medical Pluralism in Dar es Salaam: Globalisation or Glocalisation?", International Relations, 2005, vol. 19, n4, pp. 457-473.

51. EBM "Evidence Based Medicine," see following note. We should add that this model of scientific validation tends towards an increased rationalisation of medical practices and produces a regulatory medicine at the expense of a clinical medicine. Cf. Alberto Cambrosio, "Rationalisation et médecine des preuves en oncologie: quelques remarques à propos de la régulation des pratiques biomédicales," Sciences Sociales et Santé, 2005, vol. 23, n4, pp. 41-48.

52. A particular stage in a set of procedures aimed at demonstrating the harmlessness and therapeutic effectiveness of a substance, composition, or biotechnology being tested as a potential therapeutic medicine or technique: it is one of the stages in the development of a medicine. Clinical trials are an integral part of what is called Evidence Based Medicine, the final strictly regulated outcome of "clinical science." See Philippe Pignarre, $L e$ grand secret de l'industrie pharmaceutique, Paris, La Découverte, 2004, 199 pp., p. 58. For a history and an anthropological analysis of clinical trials, cf. Harry Marks, Evidence Based Medicine History and Anthropology of Clinical Trials (1900-1990). 
Among many ongoing and future research projects, the Herbalome project, which is large-scale and long-term (15 years), is due to be launched soon. Its objective is the close examination of TCM products, and the methods used include high level screening, toxicity tests, and clinical trials to identify the active substances and toxic substances in 400,000 TCM compositions and 10,000 vegetable and animal extracts. ${ }^{\left({ }^{33)}\right)}$ Moreover, TCM/Chinese medicine appears in a call for projects launched by the French NRA (National Research Agency) for the first time this year, following Franco-Chinese research agreements in partnership with biological and medical sciences in the Biotechnologies for Health Programme ${ }^{(54)}$ : "The BiotechS programme is opening up internationally in 2009 with the possible participation of Chinese partners in projects dealing with the study of traditional Chinese medicines. These international projects will be evaluated according to the same procedures and by the same committees as French projects." Key words in the programme include biomarkers, biomaterials, sifting, clinical trials, immunotherapy, non-medical imagery, and therapeutic innovation. In short, they refer to biotechnologies based on innovative scientific concepts that exploit cutting-edge technologies in biology and medicine.

\section{Clinical trials and treatments for AIDS}

Consensually at the level of concepts and practice, clinical trials are ideally carried out in four stages. Stage I tests and determines the dose that triggers the initial desired and undesired pharmacological effects, usually on healthy subjects numbering 20 at most. During Phase II, pharmacological effectiveness is evaluated with the establishment of optimal dosage and efficient posology. The therapeutic index determines the relation between the prescribed dose and the toxic dose. This stage still poses unresolved problems to researchers, and difficulty varies according to the pathology. Phase III consists of applying a particular methodology based on comparisons between homogenous groups of patients, with one receiving the product and the other a reference product or a placebo. In order for both groups to be identical, a draw is carried out called randomisation. In order to prevent an induction phenomenon, the test is carried out "double blind": none of those concerned knows the result of the randomisation. Inclusion criteria for patients, who range in number from 100 to several thousand, are very precise and selective. This methodology defines doubleblinded randomised and placebo-controlled clinical trials. Phase IV, known as "pharmacovigilance," consists of testing the effectiveness and tolerance to the product in normal prescription conditions, and in ordinary clinical practice.

I have briefly described the complete methodology of a "normalised" test employed by the scientific community and pharmaceutical industry as a condition for licensing a medicine for sale in order to give an idea of the complexity of the process of researching and developing a medicine or biotechnology for therapeutic use, from the identification of a substance, composition, or molecule to the marketing of the final product.

To continue this analysis with a more specific case study, we should note that medical research, which ideally tends towards "normalisation" according to the EBM model, has shown potential but no really significant progress in treatments for HIV/AIDS using natural products. After a decade of extensive research aimed at discovering natural anti-HIV agents, a certain number of natural products have been selected for their specific actions and their low toxicity. Most of them have the potential to interfere with successive anti-viral targets, which can produce action mechanisms that complement those of available anti-viral medicines. However, the other aspect of the problem concerns the inadequately explored interactions between natural anti-HIV products and biomedical treatments, which in some cases can make the treatments ineffective or harmful. ${ }^{(5)}$

In 2005, although no plant-based medicine was currently being used in clinical practice for treating AIDS, a certain number of natural plant-based preparations were identified as potentially anti-viral and were tested in a clinical trial framework. ${ }^{(56)}$ In 2000, a review of the literature on the results of the treatment of HIV/AIDS with Chinese medicine - acupuncture and pharmacopoeia - concluded that despite promising indications of the reduction of certain symptoms, the published results were not convincing and showed methodological weaknesses. ${ }^{(57)}$ At that time it was possible to identify two kinds of studies: one focused on symptomatic relief, for example of diarrhoea and neuropathy, while the

53. "TCM under the microscope: Researchers hope the project will lead to better quality control," Science, 12 February 2008.

54. http://www.agence-nationale-recherche.fr/AAPProjetsOuverts? Nodld= 17\&IngAAPId=227, page visited on 15 January 2009, pdf programme, p. 83.

55. See Edward Mills, Victor Montori, Dan Perri, Elizabeth Phillips, Gideon Koren, "Natural health product-HIV drug interactions: A systematic review," International Journal of STD and AIDS, 2005, n¹6, pp. 181-186.

56. See an overview of the situation, including a review of publications, by Inder Pal Singh, Sandip B. Bharate, K.K. Bhutani, "Anti-HIV natural products," Current Science, 2005, vol. $89, n^{\circ} 2$, pp. 269-290.

57. Acupuncture Research Resource Center (ed.), "HIV Infection and Traditional Chinese Medicine: The evidence for effectiveness," Briefing Paper $n^{\circ} 6$, British Acupuncture Council Publ., February 2000. 
other explored the use of Chinese medicine in combination with ARV treatments to alleviate side effects and optimise the effective treatment. Controlled clinical trials attesting to the effectiveness of Chinese medicine based on biomedical markers of HIV ${ }^{(58)}$ infection should be carried out in the framework of future research. ${ }^{(59)}$ At a methodological level, the objective will be to normalise clinical trials in traditional medicine according to international biomedical standards.

\section{Clinical trials of AIDS treatments in China}

In the 2000s, following a trend observed in emerging and developing countries, clinical trials in China have undergone unprecedented development. We should remember that for a decade the country has been accelerating along the path of economic and cultural globalisation, including that of the world health market. We should note that China has very recently integrated the WHO system for the registration of clinical trials, ${ }^{\left({ }^{60)}\right.}$ and that this procedure allows Chinese data to be submitted to the WHO research site on the Internet. The Chinese Register of clinical trials was initiated in 2005, and in less than two years was recognised as compliant with the norms. According to Margaret Chan, Director General of the WHO, the efforts of the Chinese and Indian governments toward this integration reinforce the international movement for transparency and distribution of information from research circles to the public.

In this context, even innovative treatments for AIDS are tested in traditional medicine and in biomedicine. ${ }^{(61)}$ Thus the legitimisation process for TCM includes validation based on the evidence provided by biomedical testing: proof of the biological effectiveness and harmlessness of a composition or technique being tested has to be provided according to EBM evaluation criteria in order for these "AMC" treatments to be validated by the international scientific community and given a permit to be sold on the market. ${ }^{(62)}$

It was in 1985 that the first seropositive person was discovered in China, and in that same year the first clinical trials of treatment for HIV by the pharmacopoeia were carried out at the Quan Yin Center in San Francisco by Dr. Misha Cohen's team. This team also carried out the first double blind randomised and placebo-controlled test of a Chinese pharmacopoeia treatment of the symptoms associated with $\mathrm{HIV}$, the results of which were published in an international journal. ${ }^{(63)}$

According to the results reported in a number of Chinese academic publications on clinical trials of AIDS treatments,
TCM research shows advances in the identification of plants, in the extraction of the most active substances, and in the testing of medicinal compositions: out of 1,000 species of plants commonly used in the pharmacopoeia, more than 100 have an anti-viral effect and several dozen inhibit the spread of HIV. ${ }^{(64)}$ These publications confirm that animal, vegetable, or mineral extracts can be conceptualised and ultimately categorised as medicinal products on the biomedical model without any explicit reference to TCM theory and practice.

Compounds of CATCM-II (Zhongyan-2) and CATCM-IV (Zhongyan-4), both of which are innovative TCM treatments undergoing clinical trials, bear the name of the institution that tests them: the China Academy of TCM (Zhongguo zhongyi yanjiuyuan), formerly CACMS (Zhongguo zhongyi kexueyuan). Testing stages have been carried out in the framework of the TCM treatment of HIV/AIDS project, which was implemented with the collaboration of 50 Chinese researchers with the Muhimbili Medical Centre in Tanzania over a period of 17 years. This project produced an accumulation of clinical trials and the publication of more than 100 articles. In terms of existing medicines in development, the Tang herbal tablet has been approved by the SFDA and can be marketed in China,

58. Such as the viral charge and the CD4 count: HIV infection triggers a chronic reduction in T lymphocytes and compromises the normal function of the immune system of those infected. A CD4 (Cluster of differentiation 4), glycoprotein on the surface of the lymphocytes ( $T$ cell), monocytes, macrophages, and dendritic cells is a primary receptor used by HIV as an entryway to T host cells.

59. Acupuncture Research Resource Center (ed.), op. cit.

60. "China and India join the WHO international clinical trials registration system," press release, 27 July 2007, http: //www.who.int/mediacentre/news/releases/2007/pr41/fr/ index.htlm, page visited on 6 August 2007.

61. For examples of biomedicine research in the framework of the development of preventive or therapeutic vaccination research, see Evelyne Micollier, "AIDS medical research, an exploratory Inquiry," poster 535, session 26.4, AIDSimpact International Conference, Marseilles, 1-4 July 2007; for an overview of biomedicine research projects in progress (in epidemiology, virology, immunology, clinical treatment, and vaccine development) in the framework of the China CIPRA programmes, see China CIPRA Reference book, op. cit, 2007, pp. 30-93; Shao Yiming, "HIV/AIDS research in China: Arising up from skyline," Chinese Medical Journal, 2006, vol. 119, n²3, pp. 1939-1940.

62. On public policies dealing with the use of CAMs and their validation, see WHO Fact Sheet 271 Traditional and Alternative Medicine, 2002, and "Stratégies de l'OMS pour la médecine traditionnelle (2002-2005)"; White House Commission on Complementary and Alternative Medicine Policy, Final Report, Washington D.C., 2002. On the concepts and evidence of CAMs, cf. Evelyne Micollier, "Experimenting on scientific versus traditional treatments: The case of AIDS medical research in China," Proceedings of the International Congress on Logic, Methodology and Philosophy of Sciences (LMPS), Beijing, 8-15 August 2007, London, King's College Press, 2009, in press; Christine Ann Barry, "The role of evidence in alternative medicine: Contrasting biomedical and anthropological approaches," Social Science and Medicine, 2005, n62, pp. 2646-2657.

63. Jeffrey H. Burack, Misha R. Cohen, Judith A. Hahn, Donald I. Abrams, "Pilot Randomized Controlled Trial of Chinese Herbal Treatment for HIV-Associated Symptoms," Journal of AIDS, 1996, vol. 12, n4, pp. 386-393.

64. Cf. Wu Gang, art. cit., p. 83. 
while tests of the Qiankunning capsule, the Keaite capsule, the Chuankezhi injection, the Aining granule, and the Sanhuang composition are underway or have been completed. ${ }^{(65)}$ The SFDA's functions primarily concern the safety of food and health products, but also include supervision of research protocols and clinical trials submitted for the organisation's prior approval.

Let us take the example of the publication by Ma et al. ${ }^{(6)}$ resulting from the clinical trial aimed at testing the effectiveness of the Aikeqing capsule in treatment combined with $A R V$ s, in order to shed light on the problem of evaluating results. The protocol describes a clinical trial that will lack scientific validity, regardless of its outcome, since its inclusion of only eight patients without a control group does not meet the international norms for a double blind random trial. However, some clinicians see the results as showing some therapeutic effectiveness. This kind of clinical research could be validated to some extent in a pre-EBM framework. It is not merely a clinical trial dependent on the subjectivity of one practitioner. Thus the toxicity of TCM products was traditionally documented by clinical trial, while the most modern toxicity data are based on animal testing in the framework of pre-clinical trials. ${ }^{(67)}$

The initial results of documentary research ${ }^{(68)}$ show that the most widely-used treatments are commonly used in the daily lives of people and families to maintain health, stimulate the immune system, and improve the overall immunity of the body. A very small number of treatments tested are TCM innovations - for example the Zhongyan-1 to Zhongyan-4 compounds.

To give an idea of innovative treatments tested according to the methodology of random double blind trials with a control group under placebo, I will give some indications regarding the Zhongyan-4 composition taken from the results published by Wang et al. ${ }^{(69)}$ The product tested, prepared by the Tianjiang Pharmaceutical Company based in Jiangsu, includes extracts of "Ginseng root, Astragalus root (Radix Astragali), Fructus lycii, Radix Fricosanthis, Radix Scutelleriae, Herba Vilae, etc." The article concludes that the preparation has a function of protection and/or reconstruction of the immunity of patients with early and intermediatestage AIDS infection, contributes to reducing the power of the virus, increases body weight and improves certain symptoms. ${ }^{(70)}$ The first two components mentioned, Ginseng root and Astragalus root, have a long history in the corpus of the pharmacopoeia, indicated for immune deficiency with the main function of stimulating the immune system. Constituents in the second component are the object of research at an international level that has begun to produce encouraging results reported in an international journal of immunology. ${ }^{(71)}$ Moreover, Curcumin, a major constituent of natural curcuminoids extracted from plants, has an effect against AIDS, according to another recent publication. ${ }^{(72)}$

We should note that the treatments tested in the framework of clinical trials are usually pharmacopoeia (zhongyao) compositions and prescriptions, possibly accompanied by a complementary treatment (zhenjiu, qigong), although acupuncture-moxibustion and qigong treatments are described, for example, in Song et al. ${ }^{(73)}$ I was struck, moreover, by the interest shown by one of my interlocutors, D., the deputy director of the research institute concerned, in qigong treatments, the use of which has always been more or less called into question by health professionals and authorities in the institutional framework. All the same, D. believed that he was not yet sufficiently qualified to treat or begin research on the treatment of AIDS by qigong. ${ }^{(74)}$

65. See Wu Gang, art. cit., pp. 81-82; Evelyne Micollier, "Neo-traditional treatments for AIDS in China: National AIDS treatment policy and local use of TCM (Traditional Chinese Medicine)," abstract 345, session 8.5, paper presented at the AIDSimpact International Conference, Marseilles, 1-4 July 2007.

66. Ma Boyan, Fu Linchun, Cai Weiping, et al., 2007, "Aikeqing jiaonang dui kang bingdu shun chuan lu liaofa de zeng xiao jian du zuoyong" (Clinical effect analysis of aikeqing capsule combined with HAART as cure for HIV/AIDS), Zhongguo shiyan fangji xue zazhi (Chinese Journal of Experimental Traditional Medical Formulae), vol. 13, n8, pp. 60-63.

67. Cf. Albert Y. Leung, "Traditional Toxicity Documentation of Materia Medica-An Overview," Toxicologic Pathology, 2006, n³4, pp. 319-326.

68. The results of clinical trials are commonly published in a number of national or provincial Chinese medical journals specialising in TCM (for example, Zhongyi zazhi, Journal of TCM), in integrative medicine (Zhongxiyi jiehe xuebao, Journal of Integrative Medicine), and in (bio)medical sciences without any reference in Chinese to the typology of knowledge (Zhongguo yiyao xuebao, Chinese Journal of Pharmacology), etc., and very rarely in an international medical journal (Journal of AIDS). Cf. Joseph H. Burack et al., op. cit.

69. Wang Jian, Yang Fengzhen, Zhao Min, Zhang Yunhui, Zhang Yongxiang, Liu Ying, et al., "Randomized Double-blinded and Controlled Clinical Trial on Treatment of HIV/AIDS by Zhongyan-4," Chinese Journal of Integrative Medicine (Zhongguo jiehe yixue zazhi), 2006, vol. 12, n¹, pp. 6-11, English language edition.

70. Wang Jian et al., op. cit., conclusion of the abstract.

71. Steven Russell Fauce, Beth D. Jamieson, Allison C. Chin, Ronald T. Mitsuyasu, Stan T. Parish, Hwee L. Ng, Christina M. Ramirez Kitchen, Otto 0. Yang, Calvin B. Harley, and Rita B. Effros, "Telomerase-Based Pharmacologic Enhancement of Antiviral Function of Human CD8+ T Lymphocytes," The Journal of Immunology, 2008, n¹81, pp. 7400 7406; for a commentary aimed at popularisation of this publication, which seems, however, to somewhat over-interpret the results, see "AIDS Breakthrough: Astragalus Root Could Replace HIV Drugs," 13 November 2008, //www.naturalnews.com/0244799.html, visited on 15 November 2008.

72. Hideji Itokawa, Qian Shi, Toshiyuki Akiyama, Susan L. Morris-Natschke, Kuo-Hsiung Lee, "Recent Advances in the investigation of curcuminoids," Chinese Medicine, n³, 2008, 13 pp., accessible online, http://www.cmjournal.org/content/3/1/11.

73. Song Chunxin, Wei Jian'an, Jing Yan, Sun Limin, "Zhongyi dui huodexing mianyi quexian zonghe zheng de renshi ji zhiliao gaikuan" (General situation on TCM AIDS treatment and knowledge), Liaoning Zhongyi xueyuan xuebao (Journal of Liaoning College of TCM), 2006, vol. 8, n¹, pp. 32-33.

74. I had already observed a method of medical qigong aimed at treating cancers and AIDS in the early 1990s in Guangzhou, described in Evelyne Micollier, "Le qigong chinois : enjeux économiques et transnationalisation des réseaux, pratiques et croyances," Journal des anthropologues, 2004, $\mathrm{n}^{\circ}$ 98-99, pp. 107-146. 
It is clear, therefore, that a number of obstacles remain on the path of marketing traditional products and practices.

\section{Conclusion}

The results of clinical trials of TCM AIDS treatments do not for the moment reveal any significant advance as recognised by the international scientific community, even if some international-level publications report encouraging results. In China, a single product, the Tang herbal tablet, has been licensed for the market, and its use is now recommended in the clinical practice of combined treatments. As has been stated by $\mathrm{Cao}$ Yunzhen, immunologist and head investigator of the axis concerned with clinical research into AIDS on the China CIPRA programme, no specific category of medicine has been identified as inhibiting the spread of the virus and rebuilding the patient's immunity. ${ }^{(75)}$ Having said that, the use of TCM in treatments, follow-up, and research has an important place in Chinese public health policies. The role given to contemporary TCM, reinforced by its place as a knowledge established as an icon of national identity, is underpinned by the validation and legitimisation of a combined scientific and traditional rationality. As I have sought to demonstrate in this article, this legitimisation tends to be based on the EBM model, thus reflecting a current tendency in biomedical research, as well as on an invented or reinvented model of knowledge drawn from the source of Chinese cultural heritage.

In this context, the use of TCM in AIDS treatment is promoted in the framework of national management of the epidemic. This role can also be explained by more pragmatic factors: the unresolved problems previously mentioned here, which affect the extension of treatment and follow-up, including what is still very limited access to second-line ARV treatment regimes, as well as, from an economic perspective, the urgent need for innovation in order to survive in the face of international competition in the Chinese pharmaceutical industry sector, can also be factors that explain the official position vis-à-vis traditional medicine. Since 2004, ARV treatment regimes provided free of charge in the framework of the national programme have been the object of discussion and sharp criticism reflecting conflicts of interest between various categories of national/global, economic, and political actors. ${ }^{(7)}$ In fact, in China today, access to secondline treatments is still limited to the framework of pilot schemes, and while first-line treatments remain more economical, they do not offer the best combinations, particularly because they are associated with the development of re- sistance and generate particularly strong side effects, a fact that tends to encourage the abandonment of treatment and non-observant behaviours. These inconveniences or deficiencies, inherent in the prescribed medicinal regimes, can facilitate the acceptance of traditional medicine by patients as integrative treatment and even as an alternative treatment. In an oral presentation at the WHO Conference on traditional medicines (7-9 November 2008), Deputy Health Minister and Director of the SATCM, Wang Guogiang, referred to the use of TCM only as a treatment complementary to or combined with the HAART programme, and reaffirmed the principles inscribed in the national programme for the prevention, treatment, and follow-up of AIDS, which recommends prescribing TCM in a manner "integrated" with biomedical treatments as an asset available in the national culture to be developed in fundamental and applied research.

Nevertheless, given that TCM treatments and research are not yet standardised, and that interactions between biomedical and traditional medicines are not sufficiently documented, the use of TCM in combined treatments generates strong controversy in the world of clinical practice and research, public health, and health administration. From the patients' point of view, popular perception can differ from that of health professionals, and depart from a scientific rationality that values only experimental proof while ignoring the existence of other rationalities. Within the Chinese world, in Hong Kong, which enjoys special status in the People's Republic, and where over 95 percent of the population is Chinese, Chinese medicine is typically considered a complementary follow-up to Western medicine. ${ }^{(77)}$ According to a recent study, use of TCM does not seem to have significant influence on HAART regimes among the population concerned; ${ }^{(78)}$ the majority of patients consume traditional products following a reasonable time interval after taking ARV, in order not to reduce its effectiveness. The discussion concerning the use of traditional medicine in China

75. Cao Yunzhen, "HIV Treatment by Chinese Medicine: Exploration and Expectation," paper presented at the Fifth China CIPRA Annual Meeting, Beijing, 16-18 April 2007.

76. On the problems raised by the national HAART programme, see Joan Kaufman et al., op. cit., Chap. 5, 6, 9; documents de MSF-Beijing, 2006, in particular, "A Report by MSF. Antiretroviral Therapy in China: Outcomes and Lessons Learned after Two-years' Experience of the MSF Nanning Program," MSF French Section, August 2006, bilingual English/Chinese edition, $32 \mathrm{pp}$.

77. Cf. Ralph P. Lee, "Problems of primary health care in a newly developed society: Reflections on the Hong Kong experience," Social Science and Medicine, n¹7, pp. 14331439.

78. Kurtland Ma, Shui-Shan Lee, Elsie K.Y. Chu, Dennise K.P. Tam, Victoria S.C. Kwong, ChoiFung Ho, Kathy Cheng, Ka-Hing Wong, "Popular Use of Traditional Chinese Medicine in HIV patients in HAART era," AIDS Behavior, 2008, n²12, pp. 637-642. 
needs to be widened to its validated use outside China in schemes to treat HIV/AIDS and other chronic illnesses such as cancer, particularly in pain relief and in palliative treatments. In the context of cultural globalisation, while certain elements are becoming more homogenous, an additional process of hybridisation on a structural and/or contextual fluctuation level is being produced through the normal flow of events. ${ }^{(79)}$

\section{- Translated by Michael Black}

\section{Glossary}

guojia shipin yaopin jiandu guanliju 國家食品藥品監督管理局

guojia zhongyiyao guanliju

simian yi guanhuai

國家 中醫藥 管理局

zhongyi

xiyi

zonghe yiliao

jiehe yixue

zhenjiu

qigong

zhongyao

Zhongyan-4

Qiankunning

Aining

四免一關懷

中醫

西醫

綜合醫療

結合醫學

針炎

氣功

中藥

中研 -4 號

乾坤寧

艾寧

Keaite

克艾特

Chuankezhi

喘可治

Aikeqing

艾可清

Tangcao

唐草

Sanhuang

三黄

minjian yiliao

民間 醫療

民間 會/派

aizibing liaofa zhongxin

艾滋病 療法 中心

Zhongguo zhongyi yanjiuyuan 中國中醫研究院

Zhongguo zhongyi kexueyuan 中國中醫科學院

Zhongguo jiehe yixue zazhi 中國結合 醫學 雜誌

fangyi ju

防疫局

weisheng ju 